\title{
Multiplex biomarker analysis biosensor for detection of hepatitis $B$ virus
}

\author{
Hua Xu ${ }^{\mathrm{a}, \mathrm{b}}$, Dayong Gu ${ }^{\mathrm{a}}$, Jian'an $\mathrm{He}^{\mathrm{a}}$, Lei Shi ${ }^{\mathrm{a}}$, Jingyu Yao ${ }^{\mathrm{c}}$, Chunxiao Liu ${ }^{\mathrm{a}}$, Chunzhong \\ Zhao $^{\mathrm{a}}$, Yunqing $\mathrm{Xu}^{\mathrm{a}}$, Shengyang Jiang ${ }^{\mathrm{d},{ }^{*}}$ and Jun Long ${ }^{\mathrm{e}, *}$ \\ anstitute of International Travel Health Care, Shenzhen Academy of Inspection and Quarantine, \\ Shenzhen, 518033, P.R. China \\ ${ }^{\mathrm{b}}$ Shenzhen Children's Hospital, Shenzhen, 518038, P.R. China \\ ${ }^{c}$ Guangdong Medical college, Zhanjiang, 524023, P.R. China \\ ${ }^{\mathrm{d} S}$ Shool of public health, Nantong University, Nantong, 226019, P.R. China \\ ${ }^{\mathrm{e}}$ Medical Inspection center, Zhujiang Hospital, Nan Fang Medical University, Guangzhou, 510280, \\ P.R. China
}

\begin{abstract}
In this paper, we report the development of a protein microarray-based biosensor for the detection of the hepatitis $\mathrm{B}$ virus (HBV) serological markers using surface plasmon resonance (SPR Printing buffer, protein immobilization time and concentration of the capture protein were optimized systematically to determine the best performance of the biosensor. Under optimal conditions, five hepatitis B markers in $20 \mu \mathrm{L}$ human serum can be simultaneously detected within 30 minutes, whereas other methods such as ELISA and PCR can detect only one marker within four hours. This platform has been validated by analysis of 35 patients known to have hepatitis B, with $85 \%$ agreement between the test platform and analysis by commercial enzyme-linked immunosorbent assay (ELISA) kits. The results demonstrate that the protein microarray with SPR displayed a sensitivity of $0.1 \mathrm{ng} \mathrm{mL}^{-1}$ for HBsAg. In addition to high sensitivity, it also shows excellent specificity, reproducibility and stability. This integrated protein microarray technique combined with SPR is a promising candidate for hepatitis B diagnosis with high-throughput.
\end{abstract}

Keywords: Surface plasmon resonance, protein microarray, hepatitis B virus, label-free, biosensor

\section{Introduction}

The phenomenon of virus-induced hepatitis becomes increasingly serious in China in recent years. According to the 2011 statistical yearbook of the Republic of China, approximately 1.4 million people were infected with viral hepatitis in 2009 , among which approximately 1000 people died of HBV or its related syndrome. Currently, the hepatitis virus is widely spread, with a global distribution. The most common hepatitis viral sub-types include hepatitis A, B, C, D and E. Each is caused by a different hepatitis virus; for example, hepatitis B is caused by the hepatitis B virus (HBV) [1], one of

\footnotetext{
${ }^{*}$ Address for corresponding: Shengyang Jiang, School of public health, Nantong University, Nantong, 226019, P.R. China. Tel.: 139-6291-5150; Fax: 0513-85228505; E-mail: syjiang@ntu.edu.cn.

Jun Long, Medical Inspection center, Zhujiang Hospital, Nan Fang Medical University, Industrial Road No. 253, Guangzhou, Guangdong, P.R. China. Tel.: 020-61643491; Fax: 020-61643010; E-mail: 41671716@qq.com.
} 
the most aggressive viruses threatening public health worldwide [2]. Approximately more than 780,000 people die each year due to the consequences of HBV. Thus, the HBV risk necessitates the development of a rapid, simple and sensitive method for HBV detection to prevent the outbreak of HBV infection.

Currently, along with the development of biological techniques, molecular biology techniques based on gene tests have been established [3-5]. Among them, PCR is the main laboratory diagnostic test for the hepatitis B virus. While robust and sensitive, this method typically requires several sample preparation processes [6]. In recent decades, researchers had been committed to the development of detection technology for HBV, and have established a number of highly sensitive and specific detection techniques [7] such as an enzyme-linked immunosorbent assay (ELISA) [8, 9], electrochemical sensor [10], a molecular beacon-based platform [11], and protein microarray. However, these techniques have inherent limitations [12], such as a labeled tracer requirement and high time comsumption, and thus do not allow real-time detection.

To overcome those limitations, we integrated protein microarray and SPR techniques as an efficient alternative for high-resolution HBV detection. Major advantages of this combination include: (1) a highly parallel assay system, which will provide more information for hepatitis B diagnosis than the single-marker test; (2) a rapid label-free test; (3) intuitionistic results; and (4) no special sample preparation is required for the samples. There are several commercial SPR techniques for HVB diagnosis [13-15]; however, these conventional SPR techniques display several drawbacks in clinical diagnostics such as complicated use, low sensitivity, and high cost.

In this paper, we report a novel method for hepatitis B detection which utilizes SPR as a biosensor platform using $\mathrm{HBsAg}, \mathrm{HBsAb}, \mathrm{HBeAb}, \mathrm{HBeAg}$, and $\mathrm{HBcAg}$ as protein probes. We optimized protein probe immobilization conditions including protein probe concentration, immobilization buffer and reaction time. The resulting platform for hepatitis $\mathrm{B}$ detection is evaluated in terms of detection limit, specificity, reproducibility and additional parameters; this biosensor platform performance agrees with ELISA. Due to encouraging results, the platform which integrates protein microarray with SPR is a very promising candidate for hepatitis B viral infection detection.

\section{Materials and methods}

\subsection{Materials}

The hepatitis B surface antigen (HBsAg), hepatitis B surface antibody (HBsAb), hepatitis B core antigen ( $\mathrm{HBcAg})$, hepatitis B core antibody $(\mathrm{HBcAb})$, hepatitis B antigen $(\mathrm{HBeAg})$ and hepatitis $\mathrm{B}$ antibody (HBeAb) were obtained from Sciarray (Shenzhen, China). N-ethyl-N-[3dimethylaminopropy] carbodiimide hydrochloride (EDC), N-hydroxysuccinimide (NHS) and 2aminoethanol hydrochloride were purchased from TCI Development Co., Ltd. (Tokyo, Japan). 12mercaptododecanoic was obtained from Shanghai Medpep Co., Ltd (Shanghai, China). Serum samples were obtained from HBV infected patients in the Shenzhen Chronic Disease Control Center, who all provided informed consent; samples were kept at $-80^{\circ} \mathrm{C}$ prior to experimental use. Samples were confirmed by commercial ELISA.

\subsection{Surface modification for protein microarrays}


Bare gold chips used for the preparation of the protein microarray were $18 \mathrm{~mm} \times 18 \mathrm{~mm}$ glass slides coated with $2 \mathrm{~nm} \mathrm{Cr}$ and $48 \mathrm{~nm} \mathrm{Au}$. These gold chips were gifts from the Science and Technology Research Center (Beijing, China). Before use, the chips were cleaned in a mixture of Milli-Q water, $30 \%$ hydrogen peroxide and $25 \%$ ammonia for 10 minutes at $60^{\circ} \mathrm{C}$, and then washed three times with Milli-Q water and ethanol, respectively. The chips were immersed overnight in $10 \mathrm{mM} 12$ mercaptododecanoic at room temperature to form a self-assembled monolayer (SAM). After SAM formation on the surface of the chips, the chips were washed with ethanol and water for 5 minutes, respectively.

\subsection{Fabrication of protein microarray}

Hepatitis B probes were prepared in a printing buffer with serial concentrations (Table 1). Acetate buffer of various $\mathrm{pH}$ values $(\mathrm{pH}=4.0,4.5,5.0,5.5)$ was used as the printing buffer. Terminal SAM carboxyl groups were activated with a freshly prepared mixture of EDC $(0.2 \mathrm{M})$ and NHS $(0.005 \mathrm{M})$ for 10 minutes. The chips were then rinsed with Milli-Q water, dried under flowing nitrogen and used immediately for protein microarray printing. The probes were spotted on the activation surface in an array format in various printing buffers; the volume of each spot was $0.4 \mu \mathrm{L}$. The schematic of the protein array is displayed in Figure 1(a), in which the numbers represent serial probes according to Table 1; the 0 spot represents the control probe. We fabricated a dual-channel model protein array to detect five biomarkers of HBV via two different methods, as shown in Figure 1(b). This array formation allowed us to simultaneously conduct two detection methods with one chip. After spotting, the printed chips were incubated at room temperature for 15 minutes. The probe-modified sensor chips were immersed in $1.0 \mathrm{M}$ ethanolamine $(\mathrm{pH} 8.5)$ for 10 minutes to inactivate the unreacted esters, and then immersed in 1\% BSA in phosphate-buffered saline (PBS) for 30 minutes to block the sensor surface.

Table 1

Preparation of probes

\begin{tabular}{lllllll}
\hline Antigen/antibody & \multicolumn{2}{l}{ Dilution proportion } & & & \\
\hline HBsAb(pH5.0) & $1: 12$ & $1: 60$ & $1: 300$ & $1: 1500$ & $1: 7500$ & $1: 37500$ \\
HBsAg(pH 4.5) & $1: 12$ & $1: 60$ & $1: 300$ & $1: 1500$ & $1: 7500$ & $1: 37500$ \\
HBeAg(pH 5.5) & $1: 8$ & $1: 40$ & $1: 200$ & $1: 1000$ & $1: 5000$ & $1: 25000$ \\
HBeAb(pH 5.0) & $1: 8$ & $1: 40$ & $1: 200$ & $1: 1000$ & $1: 5000$ & $1: 25000$ \\
HBcAg(pH 5.0) & $1: 16$ & $1: 80$ & $1: 400$ & $1: 2000$ & $1: 10000$ & $1: 50000$ \\
\hline
\end{tabular}

a

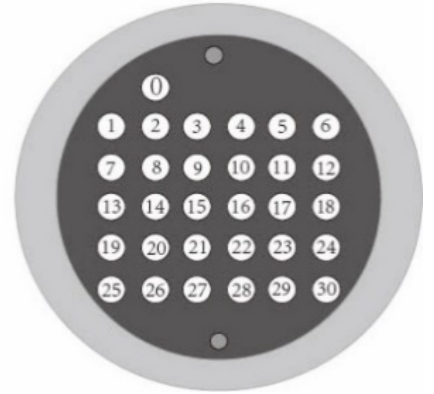

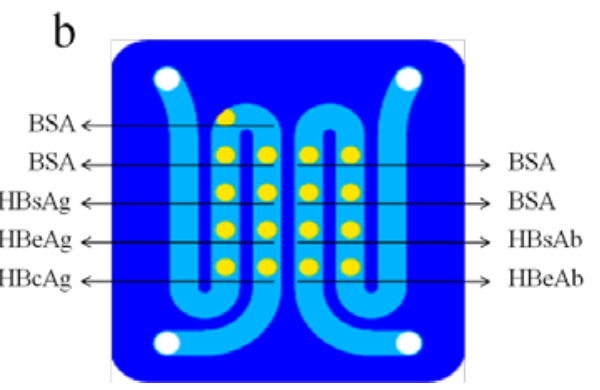

Fig. 1. Models of two protein microarrays. (a) Single-channel protein array; (b) dual-channel protein array. 
Table 2

Five HVB serological marker detection methods

\begin{tabular}{llll}
\hline Detection target & $\begin{array}{l}\text { Detection } \\
\text { method }\end{array}$ & $\begin{array}{l}\text { Capture } \\
\text { probe }\end{array}$ & Detection probe \\
\hline $\mathrm{HBsAb}$ & $\begin{array}{l}\text { Direct to detect antigen } \\
\mathrm{HBsAg}\end{array}$ & $\mathrm{HBsAg}$ & $\mathrm{HBs} \mathrm{Ag}$ \\
$\mathrm{HBeAg}$ & Direct to detect antibody & $\mathrm{HBsAb}$ & $\mathrm{HBs}$ b \\
$\mathrm{HBeAb}$ & Direct to detect antibody & $\mathrm{HBeAb}$ & $\mathrm{HBeAb}$ \\
$\mathrm{HBcAb}$ & competition immunoassay & $\mathrm{HBeAg}$ & $\mathrm{HRP}-\mathrm{HBeAb}$ \\
\hline
\end{tabular}
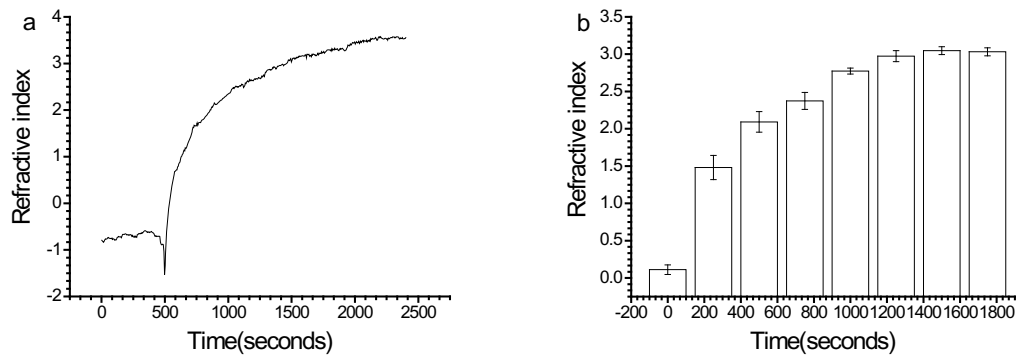

Fig. 2. Kinetics of probe immobilization on the SAM surface. (a) a typical SPR curve for probe immobilization kinetics; (b) SPR response versus incubation time for immobilization of a SAM surface probe (comparison between $1500 \mathrm{~s}$ and $1750 \mathrm{~s}$ groups was not statistically significant ( $>0.05$ ), but there was significant difference between the $1250 \mathrm{~s}$ and $1750 \mathrm{~s}$ groups; an analysis of the data of $1250 \mathrm{~s}, 1500 \mathrm{~s}$ and $1750 \mathrm{~s}$ groups shows that the signal had no significant difference; all other groups demonstrated statistically significant differences $(\mathrm{p}<0.05)$.

\subsection{Strategies for the detection of viral antigens and antibodies of $H V B$}

Because $\mathrm{HBeAb}$ exhibits cross-reactivity with $\mathrm{HBcAb}$ in human serum, we developed a competitive immunoassay to detect $\mathrm{HBeAb}$ and $\mathrm{HBcAb}$. In this study, we designed three different antigenantibody reaction strategies for the direct detection of viral antigens and antibodies of HVB (Table 2).

\subsection{SPR measurements}

All SPR measurements were performed with an SPR imager from GWC Technologies (Madison, WI). The following buffers and solutions were degassed and filtered through a $0.22 \mu \mathrm{m}$ filter: (1) running buffer, $10 \mathrm{mM}$ PBS, $\mathrm{pH}=7.4$; (2) deactivation solution, $1 \mathrm{M}$ ethanolamine, $\mathrm{pH} 8.5$; (3) regeneration solution, $0.2 \mathrm{M}$ glycin- $\mathrm{HCl}, \mathrm{pH} 2.5$. The probe-modified chip was mounted in the prismflow cell fixture, and inserted into a GWC SPR system. All SPR experiments were conducted in a PBS buffer at a constant flow rate of $2 \mu \mathrm{L} \mathrm{min}-1$ and at a temperature of $25^{\circ} \mathrm{C}$.

\subsection{Data acquisition and statistical analysis}

Statistical analysis was performed with SPSS software (Statistical Package for the Social Sciences, version 11.5, SPSS, Inc., Chicago, IL). The data was presented as means \pm standard deviation (SD). The statistical analysis was carried out by ANOVA followed by LSD; values of $p<0.05$ were considered to indicate statistical significance. 

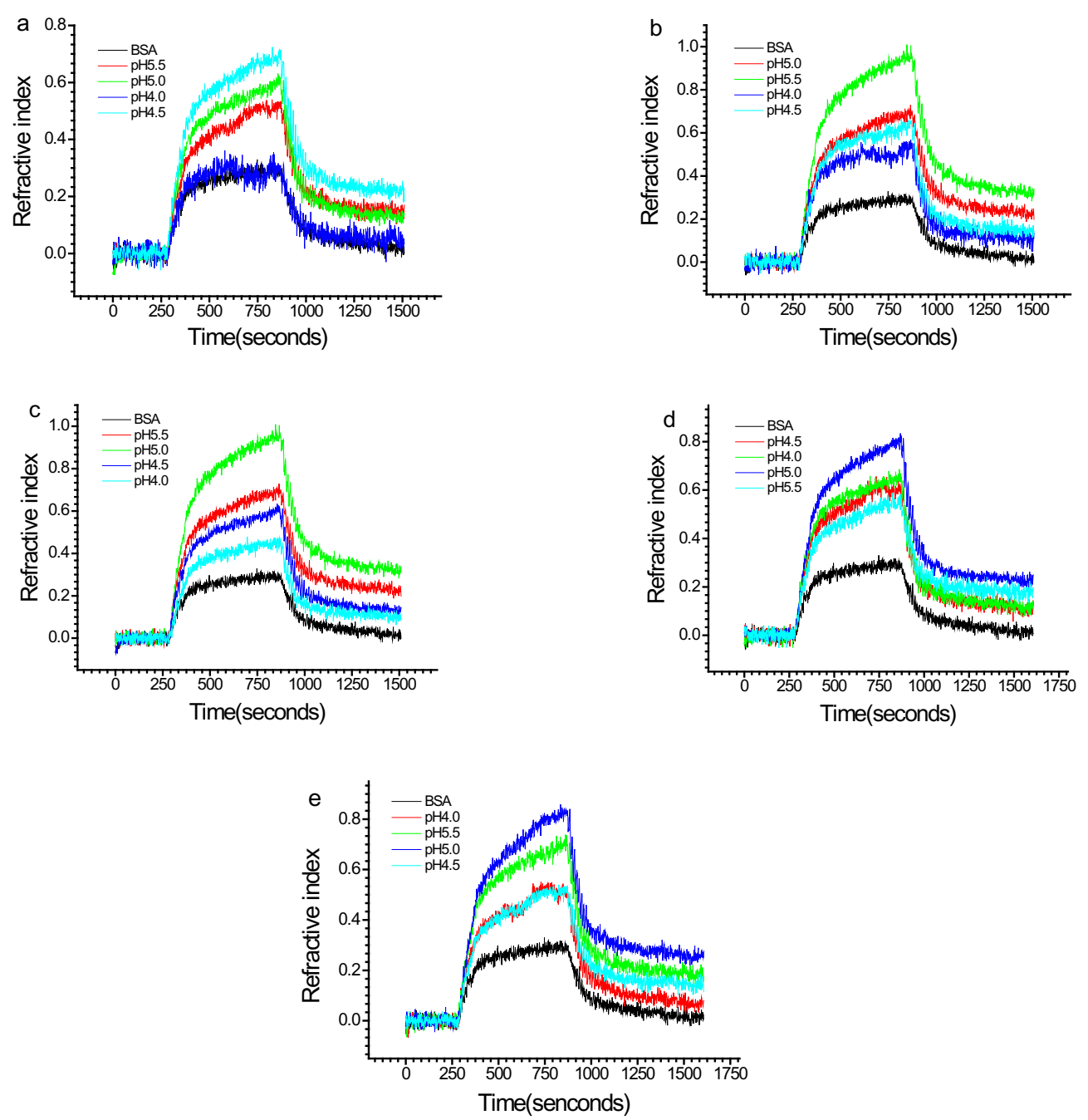

Fig. 3. The optimizal immobilization $\mathrm{pH}$ value of antigen/antibody probes: (a) $\mathrm{HBeAg}$, (b) HBsAg, (c) $\mathrm{HBsAb}$, (d) $\mathrm{HBcAb}$, (e) $\mathrm{HBeAb}$. The optimal immobilization $\mathrm{pH}$ values of the five capture probes $\mathrm{HBsAg}, \mathrm{HBsAb}, \mathrm{HBeAb}, \mathrm{HBeAg}, \mathrm{HBcAg}$ were $4.5,5.0,5.0,5.5$ and 5.0, respectively.

\section{Results}

\subsection{Optimization of immobilization time}

The effect of incubation time on probe immobilization on the SAM surface was studied by pumping $200 \mu \mathrm{L}$ of probe protein into a flow cell after the chip surface was activated with EDC and NHS solutions. The degree of probe immobilization can be calculated according to the SPR response change value. Figure 2 demonstrates that the degree of probe immobilization increased rapidly during the first 1 minute of incubation, and reached a plateau after 15 minutes. Results of the statistical analysis suggest that an incubation time of 15 minutes is sufficient for probe immobilization. 

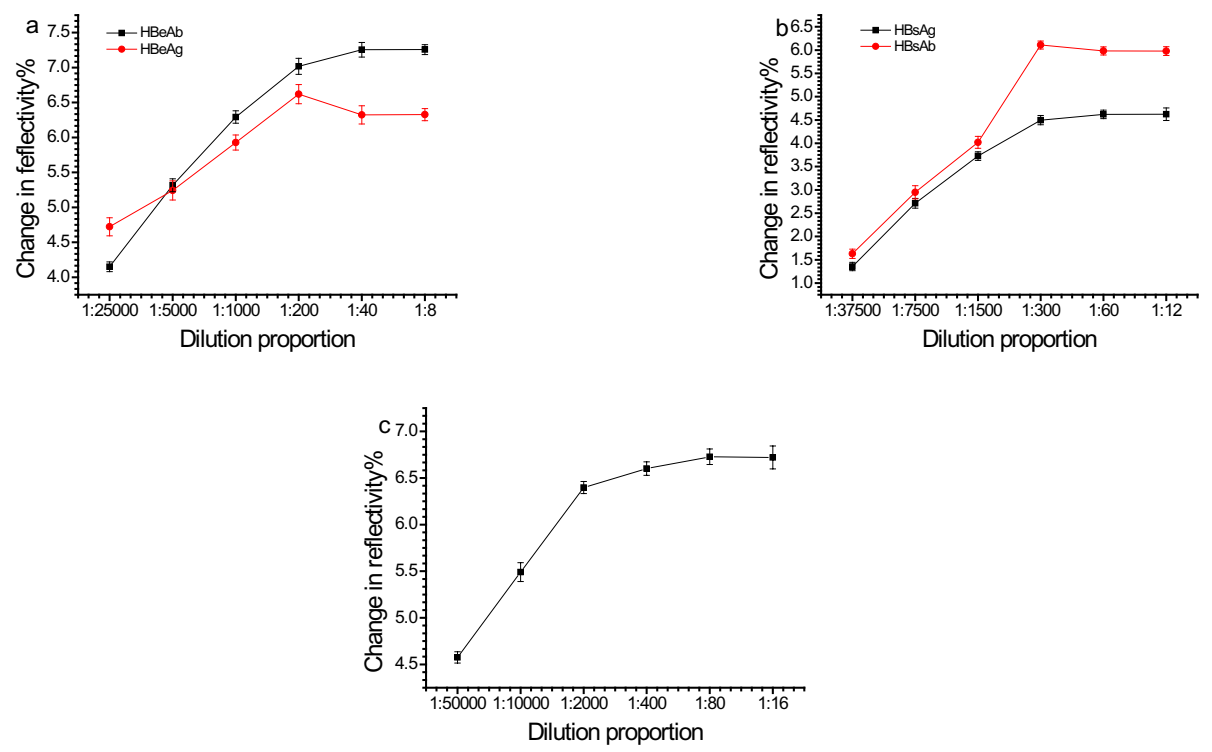

Fig. 4. The optimized concentration of antigen/antibody: (a) HBeAb and $\mathrm{HBeAg}$; (b) HBsAg and $\mathrm{HBsAb}$; (c) $\mathrm{HBcAg}$. The optimal immobilization concentration of probes HBsAg, HBsAb, $\mathrm{HBeAb}, \mathrm{HBeAg}, \mathrm{HBcAg}$, were $1: 300,1: 300,1: 200,1: 200$ and $1: 400$, respectively.

\subsection{Optimization of $p H$ value}

As the probes were dissolved in printing buffer, the $\mathrm{pH}$ value of the printing buffer will significantly affect probe activation. The recognition capacity was used to evaluate the effectiveness of probe immobilization. Probes dissolved in printing buffers of different $\mathrm{pH}$ values were immobilized on the activated sensor surface; then $200 \mu \mathrm{L}$ of reaction mixture was pumped into the flow cell. The interaction process between the probe and the target was monitored in real time using the SPR technique. Figure 3 confirms that each type of probe has a unique optimal $\mathrm{pH}$ value for immobilization depending on the probe value. The results indicate that optimal immobilization $\mathrm{pH}$ values of the five capture probes $\mathrm{HBsAg}, \mathrm{HBsAb}, \mathrm{HBeAb}, \mathrm{HBeAg}, \mathrm{HBcAg}$ were 4.5, 5.0, 5.0, 5.5 and 5.0, respectively.

\subsection{Optimization of probe concentration}

Using the optimal printing buffer and immobilization time, we investigated the effect of probe concentration on the resulting sensor performance. A serial concentration of probes in optimal buffer was printed on the SAM surface. In this study, $200 \mu \mathrm{L}$ target proteins were applied to investigate performance based on different probe concentrations. Due to the high expense of proteins, the result of this experiment will be useful in the optimization of immobilization to match requirements of high sensitivity and economy. SPR responses for specific interactions as a function of printed probe concentrations are shown in Figure 4. The response change in reflectivity increases with printed protein concentrations of protein dilution ration $>1$ :200. A slight increase occurs when the dilution ratio is lower than 1:200 for $\mathrm{HBeAb}$; this trend was also observed for $\mathrm{HBsAg}$ and $\mathrm{HBcAg}$. In contrast, with $\mathrm{HBeAg}$ and HBsAb, the signal decreases at higher than optimal concentrations. The optimal 
dilution ratios for the five probes $\mathrm{HBsAg}$, $\mathrm{HBsAb}, \mathrm{HBeAb}, \mathrm{HBeAg}$ and $\mathrm{HBcAg}$ were 1:300, 1:300, $1: 200,1: 200$ and 1:400, respectively.

\subsection{Reproducibility test}

The reproducibility of intra-arrays (three different spots in one chip) and inter-arrays (spots in three different chips) were evaluated by using $\mathrm{HBsAg}$ as a model protein. Results indicate that the coefficient variations (CV values) of intra-arrays and inter-arrays were $1.35 \%$ and $18.03 \%$, respectively, as shown in Table 3.

\subsection{Specificity test}

To test the cross-reactivity of antibodies used to detect HBsAg and HBeAg, we demonstrated their specificity using disease sera which were positive for $\mathrm{HBsAg}$ and $\mathrm{HBeAg}$. As shown in Figure 5, there is a very clear specific reaction of two HBsAg and HBeAg with their corresponding targets.

\subsection{Stability assessment of SPR protein microarray}

For reliable results in practical applications, the protein microarray should maintain high biological activity while in storage. Hence, to evaluate the stability of the protein microarray, the chips modified with probes were stored in boxes at $4{ }^{\circ} \mathrm{C}$. Detection stability tests were performed with the corresponding targets after one week, two weeks, three weeks and four weeks of storage. The protein microarray demonstrated identical signal intensities after four weeks at $4^{\circ} \mathrm{C}$, with a $\mathrm{CV}$ value of less than $5.16 \%$.

Table 3

Reproducibility of the protein chip

\begin{tabular}{|c|c|c|c|c|c|c|}
\hline & \multicolumn{3}{|c|}{ Test Number } & \multirow[t]{2}{*}{$\bar{x}$} & \multirow[t]{2}{*}{$s$} & \multirow[t]{2}{*}{$\mathrm{CV}$} \\
\hline & 1 & 2 & 3 & & & \\
\hline Inter-arrays & 5.4606 & 6.2359 & 4.3223 & 4.3847 & 0.0590 & $18.03 \%$ \\
\hline Intra-arrays & 4.4512 & 4.3384 & 4.3646 & 5.3396 & 0.9625 & $1.35 \%$ \\
\hline
\end{tabular}

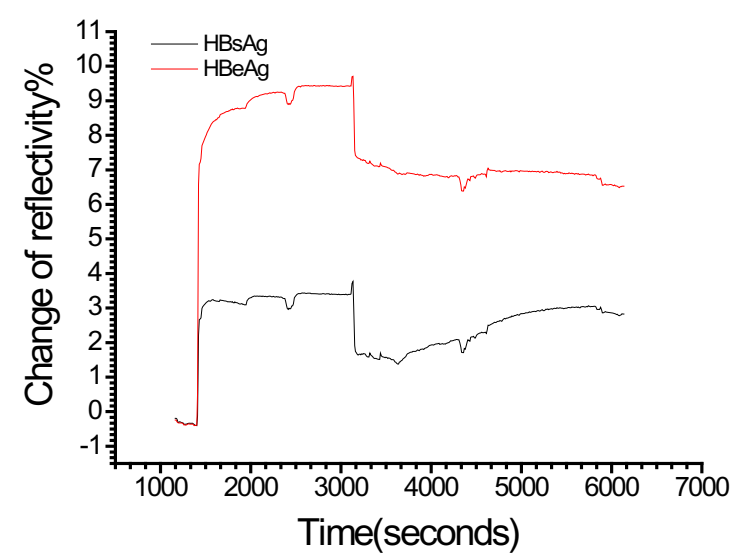

Fig. 5. Typical SPR sensorgrams for specific interaction. 

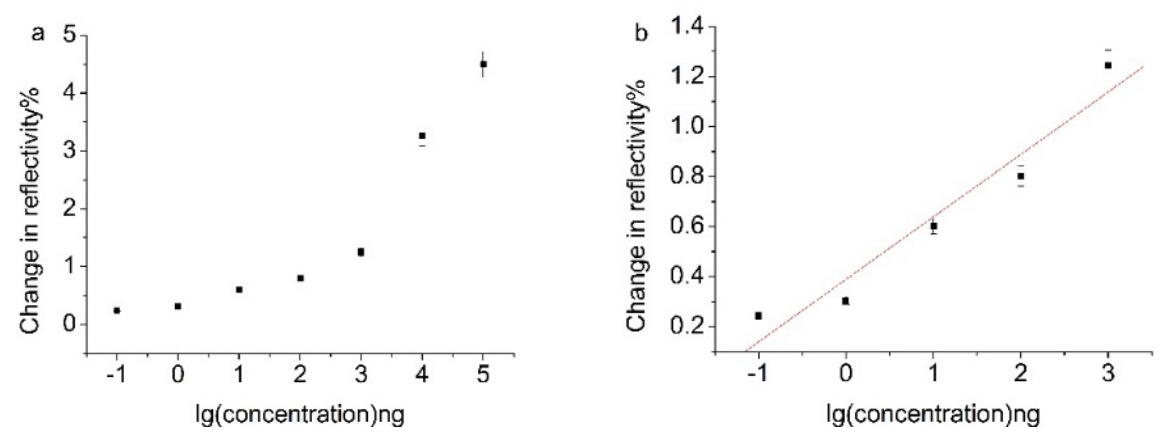

Fig. 6. SPR signal response for detection of different concentrations of HBsAg. (a) SPR response as a function of target concentrations (ranging from $0.1 \mathrm{ng}$ to $100 \mu \mathrm{g} \mathrm{mL}-1$ ); (b) a linear correlation with wider linear range from 0.1 to $1 \mu \mathrm{g} \mathrm{mL} L^{-1}$ was achieved.

\subsection{Sensitivity and linear range test}

To determine the sensitivity of the SPR protein microarray platform developed in this study, we performed SPR experiments using HBsAg as a model protein with serial concentrations $\left(0.1 \mathrm{ng} \mathrm{mL}^{-}\right.$ $\left.{ }^{1} \sim 100 \mu \mathrm{g} \mathrm{mL}^{-1}\right)$. As shown in Figure 6, the protein microarray with SPR had a sensitivity of $0.1 \mathrm{ng}$ $\mathrm{mL}^{-1}$ for $\mathrm{HBsAg}$, and a linear correlation with a wider linear range from 0.1 to $1 \mu \mathrm{g} \mathrm{mL} \mathrm{L}^{-1}\left(\mathrm{R}^{2}=0.971\right)$.

\subsection{Evaluation of protein arrays for clinical serum samples}

Under optimal conditions, we constructed a platform for a combined protein microarray with SPR for detection of hepatitis B. Thirty-five hepatitis B patients with qualitative results by ELISA were tested using a SPR protein microarray platform. Five types of hepatitis B virus serological detection marker results from the SPR protein microarray were compared to ELISA markers, as shown in Table 4; agreement between the SPR protein microarray and ELISA markers was greater than $85 \%$. Results demonstrate that the detection platform based on SPR and protein microarray is able to successfully detect five hepatitis B markers in the serum of patients in approximately 30 minutes.

Table 4

Comparison of results obtained by SPR protein microarray and ELISA for clinical serum samples

\begin{tabular}{lll}
\hline RESULTS & ELISA(n) & SPR(n) \\
\hline HBsAg + & 35 & 32 \\
HBsAg- & 30 & 29 \\
HBsAb+ & 33 & 32 \\
HBsAb- & 28 & 26 \\
HBeAg + & 28 & 27 \\
HBeAg- & 30 & 28 \\
HBeAb+ & 11 & 11 \\
HBeAb- & 9 & 7 \\
HBcAb + & 20 & 20 \\
HBcAb- & 19 & 19 \\
\hline
\end{tabular}




\section{Discussion}

Over the past decade, many studies have been conducted on the protein microarray, which is used to detect biological markers [16-18], but only a few reports are available on the protein chip which is used to simultaneously detect five hepatitis B serological markers based on SPR technology. Due to cross-reactions between $\mathrm{HBcAb}$ and $\mathrm{HBeAb}$ [19], competition testing must be used; on the other hand, labeled analytes are required by traditional test methods so that results of $\mathrm{HBsAg}, \mathrm{HBeAg}$ and $\mathrm{HBsAb}$ tests could be visualized. This method seriously hinders antigen/antibody activity and can cause environmental pollution, both of which have hindered hepatitis B detection chip development.

To overcome those limitations, this study combined SPR technology and a protein microarray to form a new detection technology. This method can not only detect five HBV serological markers in a single chip, but it also uses the direct and competition methods without simultaneous labeling. Optimum protein microarray fabrication and performance must take into consideration the factor of printing buffer, incubation time and probe concentration. We have established an SPR protein microarray platform technology for hepatitis B detection that takes advantage of a high throughput, a simplified process and a short test time. By using this platform, five hepatitis B markers can simultaneously be detected in $20 \mu \mathrm{L}$ serum in approximately 30 minutes, whereas other methods such as ELISA and PCR can detect only one marker in a four-hour period. The agreement between the protein microarray and ELISA results for 35 clinical sample tests was greater than $85 \%$. In addition, the HBsAg detection limit of this platform was $0.1 \mathrm{ng} \mathrm{mL^{-1 }}$, which meets the clinical standard. Further benefits of this platform have also been demonstrated, particularly with regard to specificity, reproducibility and stability. The protein microarray based on SPR technology is simple, quick and highly sensitive; it is a good prospect for the rapid screening of infections in early diagnosis and clinical applications.

\section{Acknowledgments}

This research is supported by Shenzhen Research Foundation for Basic Research (JCYJ20140419151618022, JCYJ20120618172144495 and CXZZ20130322112111131), Shenzhen/Hong Kong Innovation Circle (SGLH20121008144756945) National Natural Science Foundation of China (30972827, and 81171667), Guangdong Science and Technology Research Foundation (2012B031800126, 2013-cg-31).

\section{References}

[1] E. Franco, B. Bagnato and M.G. Marino, et al., Hepatitis B: Epidemiology and prevention in developing countries, World Journal of Hepatology 4 (2012), 74-80.

[2] M. Buti, F. Rodriguez Frias and R. Esteban, Quantification of hepatitis B virus HBsAg: Clinical implications, Medicina Clinica 138 (2012), 483-488.

[3] C. Eroglu, M. Zivalioglu, S. Esen and M. Sunbul, et al., Detection of hepatitis B virus in used razor blades by PCR, Hepat Mon 10 (2010), 22-25.

[4] K.R. Loeb, K.R. Jerome and J. Goddard, et al., High-throughput quantitative analysis of hepatitis B virus DNA in serum using the TaqMan fluorogenic detection system, Hepatology 32 (2000), 626-629.

[5] B. Tan, L. Qin and C. Chen, et al., Multiplex fluorescence quantitative polymerase chain reaction for simultaneous detection of hepatitis B virus, hepatitis C virus and human immunodeficiency virus, Clinical Laboratory 61 (2015), 5359. 
[6] Y. Zhao, X.Y. Zhang and Y. Hu, et al., Comparison of a novel real-time PCR assay with sequence analysis, reverse hybridization, and multiplex PCR for hepatitis B virus type B and C genotyping, Journal of Clinical Microbiology 49 (2011), 3392-3394.

[7] Y. Chen, W. Wu and L.J. Li, et al., Comparison of the results for three automated immunoassay systems in determining serum HBV markers, Clinica chimica acta; International Journal of Clinical Chemistry 372 (2006), 129-133.

[8] V. Suresh, K.A. Krishnakumar and V.V. Asha, A new fluorescent based screening system for high throughput screening of drugs targeting HBV-core and HBsAg interaction, Biomedicine and Pharmacotherapy 70 (2015), 305-316.

[9] H.L. Wang, H.Y. Zhang and Z.L. Zhai, et al., The correlation between hepatitis B virus infection and IL-27, BioMedical Materials and Engineering 22 (2012), 187-193.

[10] L. Chang, M. Howdyshell, W. Liao, C. Chiang, D. Gallego-Perez, Z. Yang, J. Byrd, L. Wu, N. Muthusamy, L.J. Lee and R. Sooryakumar, Magnetic tweezer based 3D micro-electroporation system for high throughput transfection in living cells, Small 11 (2014), 1818-1828.

[11] L. Chang, C. Liu and Y. He, et al., Small-volume solution current-time behavior study for application in reverse iontophoresis based non-invasive blood glucose monitoring, Science China Chemistry 54 (2011), 223-230.

[12] R. Xu, X. Gan and Y. Fang, et al., A simple, rapid, and sensitive integrated protein microarray for simultaneous detection of multiple antigens and antibodies of five human hepatitis viruses (HBV, HCV, HDV, HEV and HGV), Analytical Biochemistry 362 (2007), 69-75.

[13] Y.-H. Choi, G.-Y. Lee and H. Ko, et al., Development of SPR biosensor for the detection of human hepatitis B virus using plasma-treated parylene-N film, Biosensors \& Bioelectronics 56 (2014), 286-294.

[14] C. Tsung-Liang, W. Shih-Chung and L. Szu-Yuan, et al., A polycarbonate based surface plasmon resonance sensing cartridge for high sensitivity HBV loop-mediated isothermal amplification, Biosensors \& Bioelectronics 32 (2012), 8995.

[15] S. Zheng, D.K. Kim and T.J. Park, et al., Label-free optical diagnosis of hepatitis B virus with genetically engineered fusion proteins, Talanta 82 (2010), 803-809.

[16] M. Natesan and R.G. Ulrich, Protein microarrays and biomarkers of infectious disease, International Journal of Molecular Sciences 11 (2010), 5165-5183.

[17] S. Rosskopf, I. Gyurjan and J.A. Luna-Coronell, et al., The pre-analytical processing of blood samples for detecting biomarkers on protein microarrays, Journal of Immunological Methods 418 (2015), 39-51.

[18] J.L. Richens, E.A.M. Lunt and P. O'Shea, Optimisation of protein microarray techniques for analysis of the plasma proteome: Minimisation of non-specific binding interactions, International Immunopharmacology 24 (2015), 166-168.

[19] N.R. Watts, J.G. Vethanayagam and R.B. Ferns, et al., Molecular basis for the high degree of antigenic cross-reactivity between hepatitis $\mathrm{B}$ virus capsids $(\mathrm{HBcAg})$ and dimeric capsid-related protein $(\mathrm{HBeAg})$ : Insights into the enigmatic nature of the e-antigen, Journal of Molecular Biology 398 (2010), 530-541. 